\title{
Perfil demográfico da população indígena Xavánte de Sangradouro-Volta Grande, Mato Grosso (1993-1997), Brasil
}

\author{
Demographic profile of the Xavánte Indian \\ population in Sangradouro-Volta Grande, \\ Mato Grosso (1993-1997), Brazil
}

Luciene Guimarães de Souza 1

Ricardo Ventura Santos 2,3

\footnotetext{
1 Distrito Sanitário Especial Indigena Xavánte, Fundação Nacional de Saúde. Rua Xavánte 785, Barra do Garças, MT 78600-000, Brasil. lucienegsouza@uol.com.br 2 Escola Nacional de Saúde Pública, Fundação Oswaldo Cruz. Rua Leopoldo Bulhões 1480, Rio de Janeiro, $R J$ 21041-210, Brasil. santos@ensp.fiocruz.br 3 Departamento de Antropologia, Museu Nacional, Universidade Federal do Rio de Janeiro. Quinta da Boa Vista s/no, Rio de Janeiro, $R J$ 20940-040, Brasil.
}

\begin{abstract}
This paper analyzes the demographic profile of the Xavánte population at the Sangradouro-Volta Grande Indigenous Reserve in Mato Grosso, Brazil, from 1993 to 1997. The survey included annual censuses and vital statistics from 7 Xavánte villages. Permanent contact with Brazilian national society, established in the 1940s and 50s, caused a population drop due to epidemics and clashes. In 1995 there were 825 individuals in the community. The crude birth rate $(57.7 / 1,000)$ and death rate $(9.1 / 1,000)$ were higher than the national averages. The majority (56\%) of the population is under 15 years of age (median: 13 years) and the infant mortality rate is high (87.1 per thousand live births), probably resulting from precarious sanitary conditions in the villages. Other results included the persistence of polygyny; low levels of migration; a dynamic of splits and formation of new villages; traditional housing patterns maintained in the old villages and abandoned in the new ones. The recent demographic recovery in the data from Sangradouro-Volta Grande is similar to that observed in the Pimentel Barbosa community. The study highlights the importance of systematically collecting and analyzing demographic data from indigenous populations.
\end{abstract}

Key words Demography; Mortality; Fertility; Xavánte; South American Indians

Resumo Neste artigo, analisa-se o perfil demográfico da população Xavánte da Terra Indígena Sangradouro-Volta Grande, Mato Grosso, Brasil, no período 1993-97. O levantamento demográfico incluiu censos anuais e registros de eventos vitais da população de sete aldeias Xavánte. O contato permanente com a sociedade nacional, estabelecido nas décadas de 1940 e 50, deu origem à depopulação por epidemias e confrontos. Em 1995, existiam 825 indivíduos na comunidade. Verificaram-se taxas brutas de natalidade $(57,7 / 1.000)$ e de mortalidade $(9,1 / 1.000)$ superiores às médias nacionais. Na população, predominam (56\%) os menores de 15 anos de idade (mediana: 13 anos) e há elevada taxa de mortalidade infantil (87,1 por mil), decorrente provavelmente das precárias condições sanitárias das aldeias. Outros resultados: persistência da poliginia; baixos níveis de migração; dinâmica de cisão e formação de aldeias; padrões tradicionais de residência mantidos nas aldeias antigas e abandonado nas novas. Há semelhança entre a recente recuperação demográfica do conjunto de dados populacionais de Sangradouro-Volta Grande e a da comunidade Pimentel Barbosa. Destaca-se a importância da coleta e da análise sistemáticas de dados demográficos para as populações indígenas.

Palavras-chave Demografia; Mortalidade; Fecundidade; Xavánte; Índios Sul-Americanos 


\section{Introdução}

São praticamente desconhecidos os mais básicos aspectos da dinâmica demográfica dos povos indígenas situados no Brasil (Azevedo, 1997; Coimbra Jr. \& Santos, 2000; Ricardo, 1996). Estatísticas vitais, tais como coeficiente de mortalidade infantil, esperança de vida ao nascer e taxas brutas de natalidade e mortalidade, que são essenciais para monitorar o perfil de saúde/doença e planejar ações de saúde e educação, entre outras, não são disponíveis para a ampla maioria dos povos indígenas. Nesse sentido, Coimbra Jr. \& Santos (2000) chamam a atenção para as implicações do que denominam uma "danosa invisibilidade demográfica e epidemiológica”.

Estatísticas vitais não somente são úteis para situar demograficamente os povos indígenas no contexto sócio-político nacional contemporâneo, como também têm a potencialidade de lançar luzes sobre a trajetória histórica dessas sociedades ao longo do processo de interação com a sociedade envolvente. Como amplamente documentado, o contato e a interação com a sociedade nacional brasileira têm sido historicamente marcados por profundas transformações para as sociedades indígenas. Introdução de doenças, invasão de territórios, comprometimento da sobrevivência física e cultural, desestabilização social e das atividades de subsistência, além de drástica redução populacional, são fatos recorrentes nesse processo, todos eles com reflexo sobre a dinâmica demográfica. Dentre os poucos estudos que abordaram os impactos do contato sobre a demografia, podem ser citados Baruzzi et al. (1994), Black et al. (1978), Early \& Peters (1990), Flowers (1994), Ribeiro (1956), Wagley (1973) e Werner (1983).

O objetivo deste trabalho é apresentar a análise de um conjunto de dados demográficos coletados ao longo de um período de cinco anos em uma área indígena Xavánte. O intuito principal é caracterizar aspectos relativos ao perfil demográfico dos Xavánte de Sangradouro-Volta Grande no que diz respeito, sobretudo, à fecundidade e mortalidade, incluindo-se também aspectos relacionados à nupcialidade e à dinâmica de formação de novas aldeias nos anos 90 .

\section{População e Métodos}

\section{Os Xavánte}

As terras ocupadas pelos Xavánte localizam-se em regiões de cerrado do Planalto Central brasileiro, leste de Mato Grosso. Em 1996, a popu- lação Xavánte somava aproximadamente 8.000 indivíduos, que viviam em 70 aldeias distribuídas em seis Terras Indígenas (TI). Os dados apresentados neste trabalho foram coletados nas aldeias da TI Sangradouro-Volta Grande (cerca de 150 50' S, 530 60' W) no período 199397. Esta TI compreende 100.280 hectares, cujos limites são o Rio das Mortes, os córregos afluentes e a BR-070, além de diversas propriedades particulares. A área é contígua à Missão Salesiana, que foi estabelecida em 1906. Os três principais pólos urbanos próximos são Primavera do Leste, General Carneiro e Barra do Garças. O acesso a Sangradouro-Volta Grande é feito através da BR-070. Estradas precárias interligam a maioria das aldeias no interior da reserva.

As referências históricas mais antigas a respeito dos Xavánte datam do século XVIII, situando-os no território do atual Estado de Goiás. Naquela época, as atividades de mineração expandiram-se na então Província de Goiás, resultando em intensificação dos conflitos entre indígenas e não-indígenas. Há registros históricos que documentam campanhas militares promovidas contra os Xavánte pelo governo colonial, bem como tentativas de fixálos em aldeamentos. No início do século XIX, os aldeamentos já estavam praticamente abandonados em decorrência de epidemias e de maus tratos. Na segunda metade do século XIX, alguns subgrupos Xavánte rumaram na direção oeste, para a região que atualmente constitui Mato Grosso, onde permaneceram relativamente isolados até o início do século XX. A partir dos anos 30, durante o Estado Novo, a "integração" do Brasil Central ao contexto geopolítico nacional tornou-se meta prioritária para o governo de Getúlio Vargas.

O contato permanente dos Xavánte com a sociedade nacional aconteceu na década de 1940. O período imediatamente pós-contato foi marcado por epidemias e confrontos que resultaram em acentuada depopulação. Mais recentemente, nas décadas de 1970 e 80, intensificaram-se os esforços, inclusive e sobretudo dos próprios Xavánte, para a demarcação de suas terras. Tal dinâmica aconteceu ao mesmo tempo em que o governo federal, através de grande esforço desenvolvimentista, incentivava por meio de benefícios fiscais a colonização do leste mato-grossense por migrantes sulistas. Informações adicionais relativas à história dos Xavánte podem ser encontradas em Flowers (1983), Garfield (1996), Giaccaria \& Heide (1984), Lopes da Silva (1992) e Maybury-Lewis (1967). 


\section{- Os Xavánte de Sangradouro-Volta Grande}

Ao contrário de outros grupos Xavánte - como, por exemplo, Areões e Pimentel Barbosa -, cujo contato com a sociedade nacional foi mediado por agentes do antigo Serviço de Proteção aos Índios (SPI) na década de 1940, aqueles que atualmente vivem em Sangradouro-Volta Grande estabeleceram os primeiros contatos permanentes com missionários salesianos em meados da década de 50. Anteriormente, ocupavam a região do Rio Couto de Magalhães, de onde se deslocaram em razão da intensificação de conflitos com fazendeiros e do grassar de epidemias. Chegaram inicialmente na Colônia de Meruri e foram posteriormente deslocados para a Missão de Sangradouro, onde se fixaram desde então (Giaccaria \& Heide, 1984; Lopes da Silva, 1992).

Nas sete aldeias existentes na TI em 1997, com exceção de São José, as casas apresentamse dispostas no padrão tradicional Xavánte, qual seja, em semicírculo, no formato de ferradura, com abertura para o curso d'água próximo; o pátio central é o local de reunião do conselho dos homens maduros (warã). Em São José, o arranjo em ferradura foi abandonado e as casas estão dispostas em dois círculos concêntricos, em cujo centro há uma grande cruz de madeira. Ademais, as casas em São José já não são construídas segundo o estilo tradicional Xavánte -, completamente revestidas de folhas de palmeira -, mas mantêm o padrão de planta circular e piso de terra batida. A maioria das residências tem paredes de alvenaria e portas de madeira. Nas demais aldeias, as casas tampouco são construídas segundo o estilo Xavánte.

A sede da Missão Salesiana de Sangradouro-Volta Grande situa-se próxima de São José e sua estrutura física engloba, além da igreja, uma escola, um alojamento dos missionários, uma serraria e uma unidade de atendimento básico em saúde. Em 1997, o atendimento ambulatorial ocorria regularmente sob a responsabilidade de uma missionária técnica em enfermagem. Nas aldeias São José, Dom Bosco e Volta Grande atuavam também monitores indígenas de saúde. Com freqüência, os Xavánte dirigem-se aos serviços de saúde dos centros urbanos próximos. Usualmente, os partos ocorrem nas próprias casas sob a assistência das mulheres mais idosas do grupo doméstico. Por ocasião da coleta de dados, a rotina de vacinação das crianças era de responsabilidade da FUNAI (Fundação Nacional do Índio) e mantida com regularidade de quatro vezes ao ano.

A sociedade Xavánte apresenta metades exogâmicas constituídas por clãs patrilineares
(Poredza'ono, Ö wawe e Topdató). Os rapazes ingressam na "casa dos solteiros" (Hö) quando têm entre 9 e 12 anos de idade, ali vivendo por cerca de 5 anos. Casam-se após concluída a iniciação, que é posterior à saída do Hö. As meninas casam-se mais cedo do que os rapazes. Em geral, o casal passa a residir no mesmo domicílio somente após o nascimento do primeiro filho.

A poliginia sororal - casamento de um homem com mais de uma mulher, de preferência irmãs biológicas ou classificatórias - é corrente entre os Xavánte. Embora a maioria das pessoas case em sua própria aldeia, não são raros os casamentos que envolvem indivíduos de distintas comunidades. A manutenção da poliginia vem sofrendo restrições sob influência da Missão Salesiana.

Tradicionalmente, o grupo doméstico é composto por famílias extensas matrilocais. A residência, após o casamento, é matri ou uxorilocal, isto é, o marido passa a residir com os parentes da esposa. Em decorrência disso, os grupos domésticos são usualmente compostos de mulheres ligadas por laços de parentesco de duas ou três gerações, seus esposos e filhos. Em Sangradouro-Volta Grande, esse modelo familiar vem sendo modificado, com arranjos domiciliares que se distanciam das famílias extensas matrilocais. Para maiores informações acerca da organização social Xavánte, consultar Giaccaria \& Heide (1984) e Maybury-Lewis (1967) .

Em Sangradouro-Volta Grande, assim como no caso de diversas outras esferas da vida Xavánte, as estratégias de subsistência passaram igualmente por profundas transformações ao longo das últimas décadas. A subsistência Xavánte incluía uma combinação de caça, coleta e agricultura (Flowers, 1983; Giaccaria \& Heide, 1984; Maybury-Lewis, 1967). Essas atividades, por diferentes razões, já não são praticadas com a mesma intensidade. As expedições de caça e coleta não foram abandonadas por completo, mesmo que a freqüência e a duração tenham experimentado redução. A restrição territorial, a sedentarização e a exploração intensiva, juntamente com o crescimento demográfico, aumentaram a pressão sobre os recursos de fauna e flora. Além dos cultígenos tradicionais, os Xavánte cultivam arroz, mandioca, banana, cana-de-açúcar e mamão, dentre outros. O arroz é a base da alimentação na maioria das comunidades, o que se deve ao "Projeto Xavánte”. Esse foi um "plano integrado de desenvolvimento" implementado pela FUNAI em várias áreas nas décadas de 1970 e 80 e que pretendia instaurar a rizicultura mecanizada em larga escala (Lopes da Silva, 1992; Santos et 
al., 1997). O “Projeto Xavánte” fracassou, mas o plantio do arroz em pequena escala persiste em algumas comunidades.

\section{Coleta dos dados}

Os dados analisados neste trabalho foram coletados no período 1993-97 e provêm de duas fontes, quais sejam, recenseamentos e registros de eventos vitais.

As informações dos censos foram recolhidas por um mesmo investigador (L.G.S.) em cada aldeia, de domicílio em domicílio, nos seguintes períodos: fevereiro-março e dezembro de 1993, abril e dezembro de 1994, julho e dezembro de 1995, novembro de 1996 e fevereiro e agosto de 1997.

Paralelamente aos recenseamentos, os registros dos eventos vitais - mortes e nascimentos - foram obtidos no ambulatório mantido pela Missão Salesiana e junto aos monitores de saúde das aldeias Dom Bosco e Volta Grande. Os dados referentes às mortes foram também investigados na Casa de Saúde do Índio de Aragarças, mantida pela FUNAI, e nos hospitais freqüentados pelos Xavánte em General Carneiro e Primavera do Leste. No caso das crianças, cartões individuais de vacinação foram preenchidos a partir das informações obtidas nos censos - conduzidos em associação com atividades de assistência à saúde -, tornando possível o acompanhamento das mortes ocorridas entre os recenseamentos.

As idades foram calculadas tanto com base em registros existentes na Missão Salesiana e no posto indígena da FUNAI quanto com base nas informações providas pelos pais das crianças. A Missão guarda registros de nascimentos desde o início da década de 1960. A maioria das crianças é batizada e freqüenta a escola mantida pela Missão.

Quanto à idade dos adultos mais velhos, esta foi estimada levando em consideração os "grupos de idade" próprios à sociedade Xavánte. Por ocasião dos rituais de iniciação durante a adolescência, os rapazes tornam-se afiliados a um dos 8 grupos de idade que se sucedem. Indivíduos adultos afiliados ao mesmo grupo de idade pertencem, em geral, à mesma faixa etária, com amplitude de 4-5 anos. Da mesma forma, as mulheres apresentam filiação discernível a um dos grupos de idade. Estudos demográficos realizados em outras áreas Xavánte já haviam feito uso dos grupos de idade para estimar a idade dos adultos (Flowers, 1994). Uma análise detalhada do sistema de grupos de idade Xavánte foi efetuada por Giaccaria \& Heide (1984) e Maybury-Lewis (1967).
As idades reportadas foram confrontadas com os registros da Missão Salesiana e os da FUNAI. Muitos adultos possuem documentação pessoal. Entretanto, a existência de tais documentos não garante a veracidade dos registros de nascimento - em particular, no caso daqueles indivíduos que obtiveram suas certidões vários anos após o nascimento.

Foram recenseadas todas as pessoas residentes em cada aldeia nas datas de coleta, inclusive as que se encontravam temporariamente ausentes. Entende-se como população residente aquela constituída por moradores habituais no domicílio, quer estivessem presentes ou ausentes na data de referência. Os ausentes foram incluídos nas contagens desde que a ausência não tenha sido superior a 12 meses em relação à data do censo. Esse parâmetro também foi utilizado para caracterizar a migração.

Por ocasião dos censos, as seguintes características sócio-demográficas dos indivíduos foram investigadas: nome, sexo, relação de parentesco no domicílio, nome dos pais, nupcialidade, fecundidade, mortalidade e, quando fosse o caso, a data de morte. Além dos dados relativos às características pessoais, foram coletadas informações quanto à composição e às características das famílias (nucleares e extensas).

Para sistematizar as informações censitárias, foram preparadas fichas por unidade domiciliar. Nestas, os registros das famílias residentes e os respectivos laços de parentesco foram anotados e atualizados anualmente. Os deslocamentos individuais ou familiares foram também registrados. Classificou-se a família como nuclear quando ocupasse sozinha um domicílio e, como extensa, quando duas, três ou mais famílias habitassem o mesmo domicílio.

Para cada ano foi organizado um banco de dados, adotando-se 31 de dezembro de cada ano como data de referência. Para cada um dos indivíduos foi feito registro codificado, contendo as seguintes informações: número de identificação, aldeia de residência, número do domicílio, nome, sexo, data de nascimento, data da morte (se aplicável), nome do pai e da mãe e nupcialidade. Após as transcrições das fichas, efetuou-se nova checagem dos dados. $\mathrm{O}$ procedimento de checagem constituiu uma etapa cujo objetivo foi detectar inconsistências e incompatibilidades eventualmente persistentes nos dados, tal como duplicidade de informações.

Para fins de classificação quanto à nupcialidade, foram definidos os seguintes critérios: solteiros, os que não vivessem ou não tivessem vivido em companhia de cônjuge; casados, os que vivessem em companhia do cônjuge; sepa- 
rados, aqueles anteriormente casados que estivessem separados de seus cônjuges e não vivessem, na ocasião, em companhia de outro cônjuge; viúvos, aqueles cujos cônjuges tivessem morrido e que não estivessem na companhia de outro cônjuge na ocasião.

Os bancos de dados foram constituídos mediante o programa dBASE III Plus e analisados no programa Epi Info (versão 6.0) e Excel 97 para Windows.

\section{Resultados}

\section{Estrutura por idade e por sexo}

Entre 1993 e 1997, a população Xavánte de Sangradouro cresceu de 760 para 920 indivíduos, ou seja, taxa de crescimento próxima de $5 \%$ ao ano. O crescimento verificado ocorreu, sobretudo, em razão de nascimentos. Ao longo dos cinco anos, 26 pessoas imigraram e 40 emigraram.

Para 1995, que é o ponto médio do intervalo 1993-1997, observa-se acentuada concentração (56\%) de indivíduos nos três primeiros grupos qüinqüenais (0-15 anos) (Tabela 1). A idade mediana é de 13 anos. A parcela de indivíduos com mais de 65 anos é reduzida, da ordem de $2,3 \%$. As características da distribuição etária e por sexo para os demais anos do período é similar àquela descrita para 1995. Ao ser examinada a população total em 1995, tem-se que o percentual de homens $(54,1 \%)$ é superior ao de mulheres.

\section{Nupcialidade}

Tomando o ano de 1997 como referência para a análise da situação conjugal, nota-se que no grupo etário de 15 a 19 anos, $49 \%$ das mulheres e $6 \%$ dos homens encontram-se na categoria "casados" (Tabela 2), o que evidencia que as mulheres casam mais cedo. No grupo de 20-29 anos, verifica-se que $73 \%$ dos homens e $93 \%$ das mulheres estão na categoria "casados". Quanto à categoria "solteiros" neste grupo de idade, observa-se que nenhuma mulher está arrolada enquanto $26 \%$ dos homens nela se enquadram. Ainda com relação a sexo e idade, verifica-se que, em maiores de 20 anos, há 21 homens e nenhuma mulher na categoria "solteiros".

No grupo etário de 30-49 anos, nota-se que nove mulheres (23\%) estão sem parceiro, ou seja, nas categorias "separados" e "viúvos". Já no caso dos homens, há somente quatro indivíduos entre 30-49 anos nas categorias "solteiros" ou "separados".

\begin{tabular}{|c|c|c|c|c|}
\hline \multicolumn{5}{|c|}{$\begin{array}{l}\text { Distribuição absoluta e relativa da população Xavánte da Terra Indígena } \\
\text { Sangradouro-Volta Grande, segundo grupo etário e sexo (masculino e feminino). } \\
\text { Mato Grosso, Brasil, } 1995 .\end{array}$} \\
\hline \multirow[t]{2}{*}{ Grupo etário (anos) } & \multicolumn{2}{|c|}{ Sexo } & \multirow[t]{2}{*}{ Total } & \multirow[t]{2}{*}{$\%$} \\
\hline & M & $\mathrm{F}$ & & \\
\hline$<1$ & 27 & 17 & 44 & 5,3 \\
\hline 1 a 4 & 76 & 81 & 157 & 19,0 \\
\hline 5 a 9 & 83 & 71 & 154 & 18,7 \\
\hline 10 a 14 & 66 & 44 & 110 & 13,3 \\
\hline 15 a 19 & 42 & 41 & 83 & 10,1 \\
\hline 20 a 24 & 45 & 33 & 78 & 9,5 \\
\hline 25 a 29 & 24 & 28 & 52 & 6,3 \\
\hline 30 a 34 & 26 & 18 & 44 & 5,3 \\
\hline 35 a 39 & 8 & 12 & 20 & 2,4 \\
\hline 40 a 44 & 5 & 4 & 9 & 1,1 \\
\hline 45 a 49 & 12 & 10 & 22 & 2,7 \\
\hline 50 a 54 & 11 & 6 & 17 & 2,1 \\
\hline 55 a 59 & 5 & 4 & 9 & 1,1 \\
\hline 60 a 64 & 3 & 4 & 7 & 0,8 \\
\hline 65 a 69 & 3 & 4 & 7 & 0,8 \\
\hline 70 e + & 11 & 1 & 12 & 1,5 \\
\hline Total & 446 & 379 & 825 & 100 \\
\hline
\end{tabular}

Dentre as 145 mulheres “casadas", 12 (8,3\%) estavam envolvidas em uniões poligínicas, enquanto seis homens estavam casados com mais de uma mulher. Todas as uniões poligínicas envolviam duas mulheres.

\section{Características das aldeias}

Em 1993 havia um total de cinco aldeias em Sangradouro-Volta Grande; em 1997, sete aldeias. Ou seja, duas aldeias foram criadas no período de cinco anos. A comunidade mais antiga, estabelecida em 1957, e sede da TI é aldeia de São José, a única com mais de 500 pessoas, tendo variado de 517 indivíduos, em 1995, a 587, em 1997. Em 1997, os contigentes populacionais por aldeia variavam de 14 (Bom Jesus) a 587 (São José) indivíduos. São José mantevese sempre como a maior aldeia, com contingente populacional variando entre $62,6 \%$ a $77,2 \%$ do total da população da TI. Ao longo do período, a aldeia Dom Bosco manteve-se como a segunda em termos de contingente populacional. São José e Dom Bosco juntas sempre somaram mais de $3 / 4$ da população da TI.

No ano de 1997, o número de indivíduos por domicílio variou entre 2 (Volta Grande) e 23 (São José e Abelhinha). A respeito da fre- 
qüência acumulada, cerca da metade dos 93 domicílios da TI apresentavam mais de nove indivíduos. Uma análise mais pormenorizada segundo aldeia revela padrão de heterogeneidade. Os aldeamentos menores - como Bom Jesus, Volta Grande, Abelhinha e Marimbú são também aqueles que exibem maior freqüência de domicílios com menor número de moradores - em geral, com menos de seis. Nessas aldeias há predomínio de domicílios nos quais residem famílias nucleares. Já nas aldeias mais antigas e de maior tamanho, predominam moradias com mais de nove indivíduos. Portanto, há diferença marcante entre aldeias recém-criadas e aquelas mais antigas no que tange à composição dos domicílios.

\section{Natalidade e fecundidade}

A taxa bruta de natalidade em 1995 foi de 58,2 por mil (Tabela 3). Em 1994 e 1997 observam-se o maior e o menor índices, quais sejam, de 64,4 e 53,3 por mil, respectivamente. As variações foram menos proeminentes nos demais anos.

A taxa de fecundidade total (TFT) no período 1993-1997 foi de 8,6. Observam-se pronunciadas variações na TFT ao longo do período investigado (Tabela 3).

Quanto às taxas específicas de fecundidade por idade, os resultados apontam para tendência de aumento a partir do grupo etário de 1019 anos, até atingir um máximo entre 20-29, declinando até o grupo de 40-49 anos. Entre
1993 e 1997, a mulher mais jovem e a mais velha que geraram crianças tinham, respectivamente, 13 e 45 anos de idade. Entre 1993 e 1997 nasceram 218 crianças, distribuídas da seguinte forma: 53 mulheres geraram um filho; 61 geraram dois; 13 geraram três. Finalmente, houve uma mulher que gerou quatro filhos. No caso de mulheres que geraram mais de um filho no período, a média dos intervalos interpartais foi de 23,3 meses.

\section{Mortalidade}

No período de 1993 a 1997, as taxas brutas de mortalidade (TBM) oscilaram entre 7,3 e 12,6 por mil (Tabela 3). Na maior parte dos anos, as TBMs oscilaram entre 7 e 9 por mil. A taxa média para o período foi 9,1 por mil, tendo sido particularmente influenciada pelo ano de 1994, quando foi de 12,6 por mil.

Como indicado na Tabela 4, verifica-se que a taxa média mais elevada da mortalidade específica no período 1993-1997 foi observada no grupo de idade de 0-4 anos, seguida do grupo etário de 65 anos e mais.

Os valores da mortalidade proporcional segundo idade estão apresentados na Tabela 5 . Destaca-se o grupo de $<1$ ano de idade. Do total de óbitos, 21 foram de menores de um ano, com mortalidade proporcional de 55,2\%. Para o grupo de 50 e mais, é pequena a proporção de mortes se comparado à mortalidade de crianças e jovens. Em suma, a maior parte das mor-

Tabela 2

Distribuição absoluta e relativa da população Xavánte de Sangradouro-Volta Grande segundo estado conjugal sexo (masculino e feminino) e grupo etário. Mato Grosso, Brasil, 1997.

\begin{tabular}{|c|c|c|c|c|c|c|c|c|c|c|}
\hline \multirow{2}{*}{$\begin{array}{l}\text { Grupo Etário } \\
\text { (anos) }\end{array}$} & \multicolumn{2}{|c|}{ Casados } & \multicolumn{2}{|c|}{ Solteiros } & \multicolumn{2}{|c|}{ Separados } & \multicolumn{2}{|c|}{ Viúvos } & \multicolumn{2}{|c|}{ Total } \\
\hline & $\mathrm{M}$ & $\mathrm{F}$ & $\mathrm{M}$ & F & $M$ & $\mathrm{~F}$ & M & $\mathrm{F}$ & $\mathrm{M}$ & $\mathrm{F}$ \\
\hline $15-19$ & 3 & 21 & 52 & 22 & - & - & - & - & 55 & 43 \\
\hline$(\%)$ & $(5,5)$ & $(48,8)$ & $(94,5)$ & $(51,2)$ & (0) & (0) & $(0)$ & (0) & $(100)$ & $(100)$ \\
\hline $20-29$ & 51 & 63 & 18 & - & 1 & 5 & - & - & 70 & 68 \\
\hline (\%) & $(73,0)$ & $(92,6)$ & $(26,0)$ & (0) & $(1,4)$ & $(7,4)$ & (0) & (0) & $(100)$ & (100) \\
\hline $30-39$ & 39 & 30 & 1 & - & - & 7 & - & 2 & 40 & 39 \\
\hline$(\%)$ & $(97,5)$ & $(77,0)$ & $(2,5)$ & (0) & (0) & $(18,0)$ & (0) & $(5,0)$ & $(100)$ & $(100)$ \\
\hline $40-49$ & 16 & 11 & 2 & - & 1 & - & - & - & 19 & 11 \\
\hline$(\%)$ & $(84,0)$ & $(100)$ & $(11,0)$ & (0) & $(5,0)$ & (0) & $(0)$ & (0) & $(100)$ & $(100)$ \\
\hline $50-59$ & 19 & 10 & - & - & - & - & - & - & 19 & 10 \\
\hline$(\%)$ & $(100)$ & (100) & (0) & (0) & (0) & (0) & (0) & (0) & $(100)$ & $(100)$ \\
\hline 60 e + & 20 & 10 & - & - & - & - & - & 2 & 20 & 12 \\
\hline$(\%)$ & $(100)$ & $(83,0)$ & (0) & (0) & (0) & (0) & (0) & $(17,0)$ & $(100)$ & $(100)$ \\
\hline Total & 148 & 145 & 73 & 22 & 2 & 12 & - & 4 & 223 & 183 \\
\hline
\end{tabular}


tes em Sangradouro-Volta Grande (55\%) entre 1993 e1997 aconteceu em crianças menores de 1 ano de idade, o que corresponde aproximadamente a $5 \%$ da população total.

Percebe-se ampla variação no coeficiente de mortalidade infantil, desde 62,5 por mil, em 1995, até 116,3 por mil, em 1993 (Tabela 3). O valor para o período total foi de 87,1 mortes por mil nascidos vivos.

A análise da tábua de vida abreviada indica que os coeficientes de mortalidade são mais elevados entre as crianças de 0-1 ano de idade (Tabela 6). Comparado aos demais grupos etários, é também elevada a mortalidade em crianças de 1 e 2 anos. A mortalidade reduz-se de modo considerável a partir dos 5 anos. Em termos da função lx, que se refere ao número de sobreviventes a partir de uma coorte de 1.000 indivíduos nascidos vivos, aos 10 anos sobreviveram 862 indivíduos. Ou seja, cerca de 14\% das crianças nascidas vivas morrem antes de completar 10 anos de idade.

\section{Discussão}

Um primeiro ponto para o qual gostaríamos de chamar a atenção relaciona-se às grandes flutuações observadas nos parâmetros demográficos ao longo do período de cinco anos investigados. Por exemplo, os valores do coeficiente de mortalidade infantil variaram entre 62,5 e 116,3 por mil, e a taxa de fecundidade total entre 6,5 e 10,7 filhos (Tabela 3). Em detalhado estudo a respeito da dinâmica demográfica dos Yanomámi, que se baseou na análise de dados coletados ao longo de 27 anos, Early \& Peters (1990) também observaram consideráveis amplitudes nas estatísticas vitais, fenômeno que denominaram "volatilidade demográfica” (Early \& Peters, 1990:30, 98). De acordo com esses autores, a volatilidade deriva, em parte, do reduzido tamanho dos conjuntos populacionais com os quais lidam geralmente os pesquisadores que trabalham com povos indígenas, o que resulta em flutuações aleatórias em virtude dos pequenos numeradores e denominadores empregados nos procedimentos de cálculo. Uma maneira de mitigar o impacto da volatilidade é o cômputo das estatísticas vitais para blocos maiores de tempo. Para os Xavánte de Sangradouro-Volta Grande, é provável que as variações nos valores das estatísticas vitais de ano para ano estejam estreitamente associadas à volatilidade demográfica, por alguns denominada "característica essencial" da demografia antropológica (Early \& Peters, 1990:30). Nas considerações que se seguem enfatizaremos os valo-
Tabela 3

Taxa bruta de natalidade (TBN), taxa de fecundidade total (TFT), taxa bruta de mortalidade (TBM) e coeficiente de mortalidade infantil (CMI) por mil. Terra Indígena Sangradouro-Volta Grande, Mato Grosso, Brasil, 1993-1997.

\begin{tabular}{lrrrrrr}
\hline Indicadores & 1993 & 1994 & 1995 & 1996 & 1997 & $1993-1997$ \\
\hline TBN & 56,6 & 64,4 & 58,2 & 56,2 & 53,3 & 57,7 \\
TFT & 10,7 & 10,4 & 7,6 & 7,7 & 6,5 & 8,6 \\
TBM & 9,2 & 12,6 & 7,3 & 7,9 & 8,7 & 9,1 \\
CMI & 116,3 & 78,4 & 62,5 & 100,0 & 81,6 & 87,1 \\
\hline
\end{tabular}

Tabela 4

Mortalidade específica por idade por mil habitantes. Terra Indígena

Sangradouro-Volta Grande, Mato Grosso, Brasil, 1993-1997.

\begin{tabular}{lrrrrrr}
\hline $\begin{array}{l}\text { Grupo etário } \\
\text { (anos) }\end{array}$ & $\begin{array}{c}1993 \\
\% \circ\end{array}$ & $\begin{array}{c}1994 \\
\% \circ\end{array}$ & $\begin{array}{c}1995 \\
\% \circ\end{array}$ & $\begin{array}{c}1996 \\
\% \circ\end{array}$ & $\begin{array}{c}1997 \\
\% \circ\end{array}$ & $\begin{array}{c}\text { Total } \\
\% \circ\end{array}$ \\
\hline 0 a 4 & 25,8 & 42,3 & 19,9 & 32,7 & 37,4 & 31,6 \\
5 a 14 & $5 / 194$ & $8 / 189$ & $4 / 201$ & $7 / 214$ & $8 / 214$ & $32 / 1012$ \\
& 0,0 & 3,9 & 3,9 & 0,0 & 0,0 & 1,5 \\
15 a 64 & $0 / 233$ & $1 / 254$ & $1 / 264$ & $0 / 284$ & $0 / 297$ & $2 / 1332$ \\
& 3,2 & 0,0 & 2,9 & 0,0 & 0,0 & 1,1 \\
65 e + & $1 / 317$ & $0 / 333$ & $1 / 341$ & $0 / 371$ & $0 / 388$ & $2 / 1750$ \\
& 62,5 & 62,5 & 0,0 & 0,0 & 0,0 & 21,5 \\
Total & $1 / 16$ & $1 / 16$ & $0 / 19$ & $0 / 21$ & $0 / 21$ & $2 / 93$ \\
& 9,2 & 12,6 & 7,3 & 7,9 & 8,6 & 9,1 \\
& $7 / 760$ & $10 / 792$ & $6 / 825$ & $7 / 890$ & $8 / 920$ & $38 / 4187$ \\
\hline
\end{tabular}

res das estatísticas vitais geradas para o conjunto de cinco anos compreendidos entre 1993-97.

Um segundo ponto a salientar diz respeito à representatividade dos resultados no que tange à trajetória histórica dos Xavánte de Sangradouro-Volta Grande. Os dados referem-se a momento recente (década de 1990) e relativamente curto (cinco anos), de modo que não podem ser tomados como representativos da dinâmica demográfica ao longo das últimas décadas. Os Xavánte experimentaram grave crise demográfica no período subseqüente ao estabelecimento do contato permanente, nas décadas de 1940 e 50. É possível que os níveis de mortalidade observados para os Xavánte de Sangradouro-Volta Grande em 1993-97, ainda que elevados, sejam inferiores àqueles de algumas décadas atrás. Dados oriundos de outras comunidades Xavánte sugerem que essa hipótese é plausível. Nancy Flowers (1994), a partir de dados coletados entre os Xavánte de Pimen- 
Distribuição absoluta e relativa dos óbitos por ano, segundo grupo etário. Terra Indígena Sangradouro-Volta Grande, Mato Grosso, Brasil, 1993-1997.

\begin{tabular}{|c|c|c|c|c|c|c|c|c|c|c|c|c|}
\hline \multirow{2}{*}{$\begin{array}{l}\text { Mortalidade proporcional } \\
\text { por cem habitantes }\end{array}$} & \multicolumn{2}{|c|}{1993} & \multicolumn{2}{|c|}{1994} & \multicolumn{2}{|c|}{1995} & \multicolumn{2}{|c|}{1996} & \multicolumn{2}{|c|}{1997} & \multicolumn{2}{|c|}{ Total } \\
\hline & $\mathrm{n}$ & $\%$ & $n$ & $\%$ & $n$ & $\%$ & $\mathrm{n}$ & $\%$ & $n$ & $\%$ & $\mathrm{n}$ & $\%$ \\
\hline$<1$ ano & 5 & 71,4 & 4 & 40,0 & 3 & 50,0 & 5 & 71,4 & 4 & 50,0 & 21 & 55,2 \\
\hline 1 a 4 & - & - & 4 & 40,0 & 1 & 16,7 & 2 & 28,6 & 4 & 50,0 & 11 & 29,0 \\
\hline 5 a 19 & - & - & 1 & 10,0 & 1 & 16,7 & - & - & - & - & 2 & 5,3 \\
\hline 20 a 49 & 1 & 14,3 & - & - & 1 & 16,7 & - & - & - & - & 2 & 5,3 \\
\hline $50 e+$ & 1 & 14,3 & 1 & 10,0 & - & - & - & - & - & - & 2 & 5,3 \\
\hline Total & 7 & 100,0 & 10 & 100,0 & 6 & 100,0 & 7 & 100,0 & 8 & 100,0 & 38 & 100,0 \\
\hline
\end{tabular}

Tabela 6

Tábua de vida abreviada, sexos combinados. Terra Indígena Sangradouro-Volta Grande, Mato Grosso, Brasil, 1993-1997.

\begin{tabular}{rrrrrr}
\hline Idade (anos) & Indivíduos & Mortes & Sobreviventes & qx & Ix \\
\hline 0 & 238 & 21 & 217 & 0,0882 & 1000 \\
1 & 212 & 3 & 209 & 0,0142 & 912 \\
2 & 198 & 5 & 193 & 0,0253 & 899 \\
3 & 189 & 0 & 189 & 0,0000 & 876 \\
4 & 189 & 2 & 187 & 0,0106 & 876 \\
5 & 173 & 0 & 173 & 0,0000 & 867 \\
6 & 166 & 0 & 166 & 0,0000 & 867 \\
7 & 162 & 1 & 161 & 0,0062 & 867 \\
8 & 147 & 0 & 147 & 0,0000 & 862 \\
9 & 131 & 0 & 131 & 0,0000 & 862 \\
10 & & & & & 862 \\
\hline
\end{tabular}

tel Barbosa, analisou os impactos demográficos advindos da experiência do contato. A autora caracterizou o período compreendido entre o final da década de 1950 e o início da década de 1970 como aquele mais crítico para o grupo de Pimentel Barbosa. Suas pesquisas identificaram abruptas alterações nas taxas de fecundidade e mortalidade decorrentes de epidemias e de desestruturação social. Entre 1957 e 1971 , apenas $46 \%$ das crianças nascidas-vivas de Pimentel Barbosa alcançaram a idade de 10 anos, comparado com $74 \%$ no período anterior a 1957 e $83 \%$ entre 1972 e 1990 . Aí foram igualmente observadas abruptas variações em outros parâmetros demográficos, como fecundidade, o que Flowers atribuiu à crise demográfica que se seguiu ao contato. É possível que os Xavánte de Sangradouro-Volta Grande tenham também passado por período de recrudescência da mortalidade nas décadas de 50 e 60, tal como verificado em Pimentel Barbosa, e que os níveis tenham caído em fase mais recente, a partir dos anos 80.

Feitas essas ressalvas, passemos a algumas considerações a respeito das características demográficas observadas.

Quando se analisa a composição etária dos Xavánte de Sangradouro-Volta Grande, verifica-se população em que a idade mediana é baixa, com $56,3 \%$ dos indivíduos apresentando idade igual ou inferior a 15 anos. Trata-se, portanto, de contingente demográfico bastante jovem. Via de regra, a predominância de jovens é o que se observa na ampla maioria das populações indígenas para as quais se dispõem de dados demográficos segundo sexo e idade (Adams \& Price, 1994), o que decorre sobretudo da elevada fecundidade. Em termos comparativos, as proporções de crianças e adolescentes em comunidades indígenas são bastante superiores a que se verifica para a população brasileira não-indígena. Enquanto mais da metade da população de Sangradouro-Volta Grande apresentava 0-15 anos de idade em 1995, segundo os dados do censo de 1991, e as percentagens para as diversas macrorregiões do Brasil eram as seguintes: Norte, $41,7 \%$; Nordeste, $39,5 \%$; Sudeste, 31,5\%; Sul, 32,0\%; Centro-Oeste, 35,3\%. Para o país como um todo, a percentagem era de 33,1\% (IBGE, 2000).

Em Sangradouro-Volta Grande surgiram duas novas aldeias entre 1993 e 1997, elevando o número de comunidades de cinco para sete. Nas novas aldeias, em geral pequenas, predominam domicílios compostos por famílias nucleares, em contraste com o que se observa nas aldeias matrizes. A propósito, intenso processo de fissão tem sido observado em praticamente todas as áreas Xavánte, o que tem resultado em crescimento espetacular na quantidade de aldeias. Conforme dados apresentados por Gra- 
ham (1995), havia 16 aldeias Xavánte em 1980, ao passo que eram $35 \mathrm{em} 1985$. Atualmente estima-se que existam por volta de 72 aldeias, ou seja, a quantidade mais que quadruplicou em duas décadas. A dinâmica de divisão de aldeias é também reflexo do facciosismo inerente à sociedade Xavánte. Não raro, os conflitos resultam em cisão das aldeias (Lopes da Silva, 1992; Maybury-Lewis, 1967). A intensificação da dinâmica de fissão desde a década de 80 parece estar relacionada a dois processos distintos, mas complementares. Por um lado, o desmembramento das aldeias permitia a ocupação de áreas mais remotas das reservas, possibilitando assim melhor fiscalização de seus limites (Lopes da Silva, 1992:376). Por outro, disputas políticas estavam em questão, visando à obtenção de benefícios materiais provenientes da FUNAI por parte das lideranças. No auge do "Projeto Xavánte”, voltado para a rizicultura intensiva, a criação de nova comunidade podia resultar em benefícios tais como carros, maquinário agrícola, sementes etc. (Graham, 1995).

A análise do estado conjugal segundo idade para os Xavánte de Sangradouro-Volta Grande corroborou, em larga medida, o que observações etnográficas já indicavam: via de regra, as mulheres Xavánte casam-se mais cedo que os homens. Assim, aos 19 anos de idade, no final da segunda década de vida, $48 \%$ das mulheres da amostra já estavam casadas, ao passo que os homens nessa situação representavam apenas $5 \%$. A partir dos 40 anos, quase a totalidade dos homens e mulheres estão casados. Mas há aspectos singulares que emergem da análise. Existe uma quantidade considerável de mulheres entre 30 e 39 anos de idade - cerca de $23 \%$ não-casadas, o que é inclusive cifra bastante superior à de homens na mesma faixa etária. Além disso, a parcela de mulheres em relações poligínicas é relativamente baixa, inferior a $10 \%$. Tais observações adquirem contornos ainda mais singulares quando contrastadas com dados oriundos de outras comunidades Xavánte. Em Pimentel Barbosa, que reúne um conjunto de comunidades Xavánte consideradas entre as mais “tradicionais” (Graham 1995:37), Flowers (1994) observou que a quase totalidade das mulheres em idade reprodutiva encontrava-se casada e que a percentagem daquelas em casamento poligínicos era da ordem de $40 \%$. É possível que a menor freqüência de poliginia em Sangradouro-Volta Grande deva-se, em parte, à influência dos missionários salesianos.

A fecundidade entre os Xavánte de Sangradouro-Volta Grande é elevada, traduzindo-se em taxa de fecundidade total (TFT) próxima de 8,6 filhos. Como observado em diversas outras populações indígenas (entre outros, Early \& Peters, 1990; Flowers, 1994; Meireles, 1988; Picchi \& College, 1994; Werner, 1983), o padrão de alta fecundidade, com TFTs da ordem de 7-8 filhos, deve estar intimamente associado a curtos intervalos intergenésicos - isto é, entre os partos -, combinados com a iniciação da fase reprodutiva logo no início da segunda década de vida, por volta dos 13-14 anos, que se estende, não raro, até os 40-45 anos. A TFT dos Xavánte é bastante mais elevada que aquela da população brasileira na década de 90. Para o ano de 1996, a TFT para o Brasil era de 2,32, variando de 2,05 (região Sudeste) a 3,01 (região Norte) (DATASUS, 2000). Nos cinco anos para os quais se dispõe de dados relativos a SangradouroVolta Grande, observou-se que a mulher mais jovem e a mais velha que geraram crianças tinham, respectivamente, 13 e 45 anos, tendo sido de 23,3 meses a média dos intervalos interpartais. Para Pimentel Barbosa, Flowers (1994:223) estimou média dos intervalos de 20,9 meses.

A análise de estatísticas vitais relacionadas à mortalidade é particularmente informativa para a discussão de questões relativas às condições gerais de vida, em particular no que tange ao processo saúde/doença. A taxa bruta de mortalidade dos Xavánte para o período 19931997 (9,1 mortes por mil) é superior àquela verificada para o Brasil (6,7 por mil em 1996), estando acima das cifras mais elevadas do país, que são as da região Nordeste $(7,8$ por mil em 1996) (DATASUS, 2000). É necessário, contudo, proceder à comparação de valores de taxas brutas com cautela, uma vez que são particularmente influenciados pela composição etária da população. Neste caso, a composição etária dos Xavánte, como apontado anteriormente, difere bastante daquela da população brasileira.

O coeficiente de mortalidade infantil (CMI) calculado para os Xavánte de Sangradouro-Volta Grande (87,1 por mil) é mais elevado do que a média nacional brasileira, de 37,5 por mil em 1996. A mortalidade infantil entre os Xavánte é superior àquela da região Nordeste $(60,4$ por mil em 1996) e chega a superar Alagoas, o estado brasileiro com o pior desempenho em 1996, qual seja, 84,2 por mil em 1996 (DATASUS, 2000). A outra informação acerca da mortalidade infantil para os Xavánte provém da pesquisa de Flowers (1994), que verificou um CMI de 70,8 por mil em Pimentel Barbosa no período 1972-1990. Este valor está abaixo daquele encontrado para os Xavánte de Sangradouro-Volta Grande, mas ainda assim é bastante superior à cifra para a população nacional.

No que tange à mortalidade proporcional, das 38 mortes registradas para os Xavánte en- 
tre 1993 e 1997, 21 ocorreram em crianças menores de 1 ano, enquanto 11, em crianças entre 1 e 4 anos. Em termos percentuais, $55,2 \%$ das mortes tiveram lugar antes de um ano de vida e $84,2 \%$, nos primeiros quatro anos. Quanto à mortalidade proporcional por idade no Brasil, para o ano de 1996, 8,3\% dos óbitos ocorreram em crianças menores de 1 ano, variando de $6,1 \%$ (Sul) a 15,6 (Norte). É a elevada mortalidade nos primeiros anos de vida que faz com que somente $86 \%$ das crianças consigam sobreviver até os 10 anos de vida.

O conjunto de observações apresentadas nos parágrafos anteriores aponta inequívocamente para uma situação de alta mortalidade entre os Xavánte de Sangradouro-Volta Grande, com níveis que rivalizam, ou mesmo superam, aqueles verificados nas macrorregiões socioeconomicamente mais desfavorecidas do Brasil. A maior concentração das mortes ocorre em crianças e são, em grande parte, causadas por gastroenterites e infecções respiratórias (Coimbra \& Santos, 1994). As condições de saneamento nas aldeias da TI SangradouroVolta Grande são precárias. A aldeia de São José, situada no mesmo local há cerca de 40 anos e com contigente populacional de mais de 500 pessoas, não dispõe de fossas. A água para consumo humano é captada em um curso d'água próximo. A possível contaminação da água por dejetos é problema de saneamento básico também existente nas demais aldeias. Em inquérito nutricional efetuado recentemente em São José, detectou-se que as crianças menores de 10 anos apresentavam freqüência de desnutrição energético-protéica de $22 \%$ e de anemia de $74 \%$ (Leite, 1998). A magnitude da desnutrição entre as crianças Xavánte é bastante mais expressiva que aquela que se verifica entre as crianças não-indígenas brasileiras (Bittencourt \& Magalhães, 1995; Monteiro et al., 1995).

\section{Conclusão}

Neste trabalho apresentamos uma análise demográfica da população Xavánte da TI Sangradouro-Volta Grande realizada com base em dados reunidos ao longo de um período de 5 anos. Um aspecto a ser destacado é que as informações foram coletadas no âmbito das atividades de assistência à saúde da FUNAI, o que comprova a efetiva possibilidade de o nível local coletar dados de importância para o planejamento, o monitoramento e a avaliação de atividades e programas. Um segundo ponto diz respeito à tônica que norteou as análises, que foi a de compreender a dinâmica populacional Xavánte a partir de uma perspectiva historicamente informada. Procurou-se interpretar os parâmetros demográficos, incluindo nupcialidade, migração, mortalidade, fecundidade, formação de aldeias, entre outros, à luz da trajetória histórica recente do grupo, enfatizando, em particular, o processo de interação com a sociedade nacional envolvente.

Os dados demográficos indicam que os Xavánte de Sangradouro-Volta Grande apresentam elevada fecundidade e mortalidade. O crescimento populacional foi pronunciado no período investigado. Com relação à mortalidade, que é dimensão particularmente importante na avaliação das condições de saúde, verificaram-se níveis bastante mais elevados que os valores nacionais, notadamente no caso das crianças. A elevada mortalidade dos Xavánte nos dias atuais tanto resulta da condição de marginalidade socioeconômica a que estão relegados quanto a exemplifica, manifestando uma de suas facetas através das precárias condições de saneamento de suas aldeias e inadequado serviço de saúde.

\section{Agradecimentos}

Agradecemos sobretudo aos Xavánte de Sangradouro-Volta Grande. Também à Fundação Nacional do Índio (FUNAI) pela liberação da autora principal (L.G.S.) para fins de realização do Mestrado em Saúde Pública na ENSP/FIOCRUZ. A Missão Salesiana de Sangradouro gentilmente colocou a nossa disposição dados relativos a datas de nascimento. A Carlos Coimbra Jr. pela leitura cuidadosa do texto e pelas inúmeras sugestões. Este trabalho foi parcialmente financiado pela Fundação Oswaldo Cruz (PAPES - Programa de Apoio à Pesquisa Estratégica em Saúde) e pelo CNPq (processo no 523367/95-3). 


\section{Referências}

ADAMS, K. \& PRICE, D., 1994. The demography of small scale societies: case studies from Lowland South America. South American Indian Studies, $4: 5-10$.

AZEVEDO, M. M., 1997. Fontes de dados sobre as populações indígenas brasileiras da Amazônia. $\mathrm{Ca}$ dernos de Estudos Sociais, 13:163-177.

BARUZZI, R. G.; PAGLIARO, H.; SOUZA E SILVA, R.; SCHIVARTCHE, V. \& MEZIARA, H., 1994. Os índios Panará: a busca pela sobrevivência. In: IX Encontro Nacional de Estudos Populacionais, Anais, vol. 2, pp. 225-242. Belo Horizonte: Associação Brasileira de Estudos Populacionais.

BITTENCOURT, S. A. \& MAGALHÃES, R. F., 1995. Fome: um drama silencioso. In: Os Muitos Brasis: Saúde e População na Década de 80 (M. C. S. Minayo, org.), pp. 269-270, São Paulo: Editora Hucitec/Rio de Janeiro: ABRASCO.

BLACK, F. L.; PINHEIRO, F. D.; OLIVA, O.; HIERHOLZER, W. J.; LEE, R. V.; BRILLER, J. E. \& RICHARDS, V. A., 1978. Birth and survival patterns in numerically unstable proto agricultural societies in the Brazilian Amazon. Medical Anthropology, 2:95127.

COIMBRA Jr., C. E. A \& SANTOS, R. V., 1994. Epidemiologic Profile of Amazonian Amerindians from Brazil, with Special Emphasis on the Xavánte from Mato Grosso and on Groups from Rondônia. Report of the World Bank. Rio de Janeiro. (mimeo.)

COIMBRA Jr., C. E. A \& SANTOS, R. V., 2000. Saúde, minorias e desigualdade: algumas teias de interrelações com ênfase nos povos indígenas no Brasil. Ciência \& Saúde Coletiva, 5:125-132.

DATASUS (Departamento de Informática do SUS), 2000. Indicadores e dados básicos, Brasil, 1997. 04 de janeiro de $2000<$ http:/ / www.datasus.gov.br/ cgi/idb97/matriz.htm>.

EARLY, J. D. \& PETERS, J. F., 1990. The Population Dynamics of the Mucajaí Yanomama. San Diego: Academic Press.

FLOWERS, N. M., 1983. Forager-Farmers: The Xavánte Indians of Central Brazil. Ph.D. dissertation, New York: City University of New York.

FLOWERS, N. M., 1994. Crise e recuperação demográfica: Os Xavánte de Pimentel Barbosa, Mato Grosso. In: Saúde e Povos Indígenas (R. V. Santos \& C. E. A. Coimbra Jr., org.), pp. 213-242, Rio de Janeiro: Editora Fiocruz.

GARFIELD, S., 1996. "Civilized" but Discontent: the Xavánte Indians and Government Policy in Brazil, 1937-1988. Ph.D. Dissertation, New Haven: Yale University.
GIACCARIA, B. \& HEIDE, A., 1984. Xavánte: Povo Autêntico. São Paulo: Editora Salesiana Dom Bosco.

GRAHAM, L., 1995. Performing Dreams: Discourse of Immortality among the Xavánte of Central Brazil. Austin: University of Texas Press.

IBGE (Fundação Instituto Brasileiro de Geografia e Estatística), 2000. Sistema IBGE de Recuperação Automática: Brasileiros natos (habitantes), ano = 1991. 04 de janeiro de $2000<$ http://www.sidra. ibge.gov.br>.

LEITE, M. S., 1998. Avaliação do Estado Nutricional da População Xavánte de Sangradouro-Volta Grande, Mato Grosso. Dissertação de Mestrado, Rio de Janeiro: Escola Nacional de Saúde Pública, Fundação Oswaldo Cruz.

LOPES DA SILVA, A., 1992. Dois séculos e meio de história Xavánte. In: História dos Índios no Brasil (M. C. Cunha, org.), pp. 357-378, São Paulo: Companhia das Letras.

MAYBURY-LEWIS, D., 1967. Akwe-Shavante Society. Oxford: Clarendon Press.

MEIRELES, D. M., 1988. Sugestões para uma análise comparativa da fecundidade em populações indígenas. Revista Brasileira de Estudos Populacionais, 5:1-20.

MONTEIRO, C. A.; BENÍCIO, M.H.D.; IUNES, R.F.; GOUVEIA, N.C. \& CARDOSO, M.A.A., 1995. Evolução da desnutrição infantil. In: Velhos e Novos Males da Saúde no Brasil (C. A. Monteiro, org.). pp. 93-114, São Paulo: Editora Hucitec.

PICCHI, D. \& COLLEGE, F. P.,1994. Observations about a central Brazilian indigenous population: the Bakairi. South American Indians Studies, 4:37-46.

RIBEIRO, D., 1956. Convívio e contaminação. Efeitos dissociativos da depopulação provocada por epidemias em grupos indígenas. Sociologia, 18:3-50.

RICARDO, C. A., 1996. A sociodiversidade nativa contemporânea no Brasil. In: Povos Indígenas no Brasil 1991/1995 (C. A. Ricardo, org.), pp. i-xii. São Paulo: Instituto Socioambiental.

SANTOS, R. V.; FLOWERS, N. M.; COIMBRA Jr., C. E. A. \& GUGELMIN, S. A., 1997. Tapirs, tractors and tapes: the changing economy and ecology of the Xavánte Indians of Central Brazil. Human Ecology, 25:545-566.

WAGLEY, C., 1973. Cultural influences on populations: a comparison of two Tupi tribes. In: Peoples and Cultures of Native South American (D. Gross, ed.), pp. 145-158, New York: Doubleday/The Natural History Press.

WERNER, D., 1983. Fertility and pacification among the Mekranoti of Central Brazil. Human Ecology, 11:227-245. 